Article

\title{
Analysis of Unit Process Cost for an Engineering-Scale Pyroprocess Facility Using a Process Costing Method in Korea
}

\section{Sungki Kim ${ }^{1}$, Wonil Ko ${ }^{1}$ and Sungsig Bang ${ }^{2, *}$}

1 Korea Atomic Energy Research Institute, 1045 Daedeokdaero, Yuseong-gu, Daejeon 305-353, Republic of Korea; E-Mails: sgkim1@kaeri.re.kr (S.K.); nwiko@kaeri.re.kr (W.K.)

2 Department of Business and Technology Management, Korea Advanced Institute of Science and Technology, 291 Deahak-ro, Yuseong-gu, Daejeon 305-701, Republic of Korea

* Author to whom correspondence should be addressed; E-Mail: ssbang@kaist.ac.kr; Tel.: +82-10-7340-3440; Fax: +82-42-350-6339.

Academic Editor: Hiroshi Sekimoto

Received: 31 March 2015 / Accepted: 14 August 2015 / Published: 18 August 2015

\begin{abstract}
Pyroprocessing, which is a dry recycling method, converts spent nuclear fuel into U (Uranium)/TRU (TRansUranium) metal ingots in a high-temperature molten salt phase. This paper provides the unit process cost of a pyroprocess facility that can process up to 10 tons of pyroprocessing product per year by utilizing the process costing method. Toward this end, the pyroprocess was classified into four kinds of unit processes: pretreatment, electrochemical reduction, electrorefining and electrowinning. The unit process cost was calculated by classifying the cost consumed at each process into raw material and conversion costs. The unit process costs of the pretreatment, electrochemical reduction, electrorefining and electrowinning were calculated as $195 \mathrm{US} \$ / \mathrm{kgU}-\mathrm{TRU}$, $310 \mathrm{US} \$ / \mathrm{kgU}-\mathrm{TRU}, 215 \mathrm{US} \$ / \mathrm{kgU}-\mathrm{TRU}$ and $231 \mathrm{US} \$ / \mathrm{kgU}-\mathrm{TRU}$, respectively. Finally the total pyroprocess cost was calculated as $951 \mathrm{US} \$ / \mathrm{kgU}-\mathrm{TRU}$. In addition, the cost driver for the raw material cost was identified as the cost for $\mathrm{Li}_{3} \mathrm{PO}_{4}$, needed for the $\mathrm{LiCl}-\mathrm{KCl}$ purification process, and platinum as an anode electrode in the electrochemical reduction process.
\end{abstract}

Keywords: pyroprocess facility; process costing method; First-In First-Out method; cost driver; unit process; unit cost 


\section{Introduction}

After the Fukushima nuclear accident in Japan, some nations in the E.U. (European Union), including Germany, are investing their resources into the development of renewable energies such as solar energy, bioenergy and wind energy. In addition, new renewable energies such as nuclear fusion and hydrogen energy are being developed [1,2].

However, renewable energies have ended up increasing electricity costs and consumer prices since it has not been possible to satisfy the demand for the amount of electricity needed for national economy growth owing to the lack of economic viability caused by the low utilization rate following changes in the weather. Moreover, renewable energies such as solar energy and wind energy merely supplement some of the energy needs instead of replacing nuclear power due to the need for large amounts of land and a large-scale power generation facility to produce large capacity electricity. Moreover, the paradox is that the climate change may be accelerated since carbon dioxide is discharged in large amounts when power is generated by using fossil fuels to reduce the risk of nuclear accidents [3]. New energy types such as nuclear fusion and hydrogen energy are expected to need considerable time until they can be commercialized since they are still in the early stage of development.

Since 2011, Russia and the U.S. have been considering power generation by utilizing shale gas that can be produced in their nations because it is estimated that the price of shale gas will be lower than that of other raw materials needed for power generation [4]. However, some are voicing their opinion that power generation with shale gas lacks economic viability compared to generation with fossil fuel owing to the recent decrease in oil prices. Shale gas still has many disadvantages such as significant technological difficulties and infrastructure even when fracking technology is used to extract shale gas since shale gas is widely dispersed [5]. Using shale gas on a larger scale requires additional investments in infrastructure. Namely, the continued investment in transmission pipelines has raised due to the wide distribution. Moreover, it is estimated that shale gas can be used for about 60 years, which is comparable to the period estimated for oil deposits. Another concern is that the climate may change due to the discharge of gas that is produced during the gas extraction process. In particular, questions over economic viability have been raised starting from 2014 since the nations that have shale gas do not have the facilities and infrastructure for supplying shale gas [6]. Accordingly, nuclear power is still today perceived as a very promising power generation technology by the emerging economic powerhouses such as China and other nations.

Korea, which is one of Asia's advanced nuclear nations, operates a total of 23 nuclear power plant units (19 PWR (Pressurized Water Reactor) units and four CANDU (CANada Deuterium Uranium) units) [7]. However, the accumulated spent nuclear fuel inventory is an impediment to the continual nuclear power generation since temporary storage facilities for spent nuclear fuel used in a nuclear power generation plant will become saturated starting from 2024 [8]. Temporary storage means spent fuel pools in nuclear power plant. Accordingly, the development of pyroprocessing technology and radioactive waste disposal technology is underway for recycling spent nuclear fuel with a long-term perspective to reduce spent nuclear fuel inventory $[9,10]$.

Pyroprocessing which is a dry recycling method, converts the nuclear spent fuel into U/TRU (TRansUranium) metal ingots in a high-temperature molten salt phase and decreases the volume of the radioactive waste to innovatively increase the economic feasibility of disposal. The pyroprocess 
consist of electrochemical reduction, electrorefining, electrowinning, TRU drawdown, U and U-TRU ingot processing, and waste salt purification and solidification. Nations with dense populations need to secure public acceptance in order to secure the land needed for a high-level radioactive waste repository. However, developing a measure for increasing public acceptance for spent nuclear fuel disposal is very difficult in reality owing to the NIMBY (Not in My Back Yard) phenomenon. Moreover, a spent nuclear fuel management policy that entails storing spent nuclear fuel temporarily for a long time before disposing the waste far away in the future violates the "Polluter Pays Principle (PPP)" since the cost of disposing the radioactive waste that the current generation generates will be "inherited" by their descendants. Accordingly, a realistically rational measure is to commercialize after developing spent nuclear fuel recycling technology that can reduce spent nuclear fuel inventory, and Korea is developing pyroprocessing technology today toward this end [11]. Going forth, it will be possible to reduce the spent nuclear fuel inventory if a pyroprocess facility is commercialized, and thus solve the saturation issue for the temporary storage facility. Moreover, it is very difficult to extract only pure plutonium since the pyroprocess produces a product in a uranium ingot format that mixes plutonium and TRU together. Accordingly, pyroprocessing technology is considered a spent nuclear fuel recycling technology with high proliferation resistance. For this reason, Korea developed the PyRoprocess Integrated inactive DEmonstration (PRIDE) facility, which is an engineering scale pyroprocessing facility of the stage that is carried out prior to the commercialization stage. Efforts are underway to prove the possibility of technology realization and economic viability using this facility and to complete the pyro-(Sodium-cooled Fast Reactor (SFR) advanced nuclear fuel cycle. In particular, the KAERI (Korea Atomic Energy Research Institute) is using 10 tons per year of simulated (SIM)-fuel, containing the depleted uranium and rare earth elements ( $\mathrm{Nd}, \mathrm{Ce}, \mathrm{La}$, etc.), and estimates pyroprocessing costs using diverse methods. This cost calculation result will serve not only as a back-up for identifying the economic viability of the pyroprocessing business, but will also serve as important information for judging the economic viability of the pyro-SFR nuclear fuel cycle, which is an advanced nuclear fuel cycle [12,13]. Against this background, this paper analyzed the methods for calculating the pyroprocessing unit cost first and foremost, and it was demonstrated that the process costing method is the most adequate method for calculating the unit cost for each process step. In addition, the unit process cost of pyroprocessing using the First-In, First-Out method and cost sharing are presented in detail.

\section{Cost Estimation Methods}

\subsection{Cost Object}

\subsubsection{PRIDE}

Korea has developed a back-end fuel cycle policy to solve the issue of saturation of the temporary spent nuclear fuel storage by pyroprocessing. Toward this end, first and foremost, it is necessary to prove the pyroprocessing technology through a pyroprocessing facility before commercialization. In the long-run, it is necessary to secure commercialization technology for the linkage among the unit processes and for the commercialization by securing pyroprocessing-specific proprietary source technology. KAERI started the pyroprocessing technology development strategy in 1997 and is 
currently operating PRIDE. The PRIDE facility design was carried out from 2007 to 2008, and construction was conducted from 2009 to June 2012. To prove the pyroprocess' possibility of technology realization, this facility was subjected to a trial operation after July 2012, and many experiments are underway today to develop advanced technology.

This facility can prove the pyroprocessing technology for the first time on Earth. The facility can be a base facility to secure pyroprocessing's commercialization technology through the results of joint research between Korea and the U.S. This joint research uses spent fuel as an experiment specimen in the U.S. Moreover, the pyroprocessing safety measure technology was developed in cooperation with the International Atomic Energy Agency (IAEA), and this is a facility that can significantly help to secure transparency in handling nuclear material. The cost object's design condition is shown in Table 1 to calculate the pyroprocessing unit operation cost. Figure 1 shows an inside view of PRIDE. In Table 1, ACPF means advanced spent fuel conditioning facility for the laboratory-scale pyroprocess.

Table 1. The main design criteria of PRIDE.

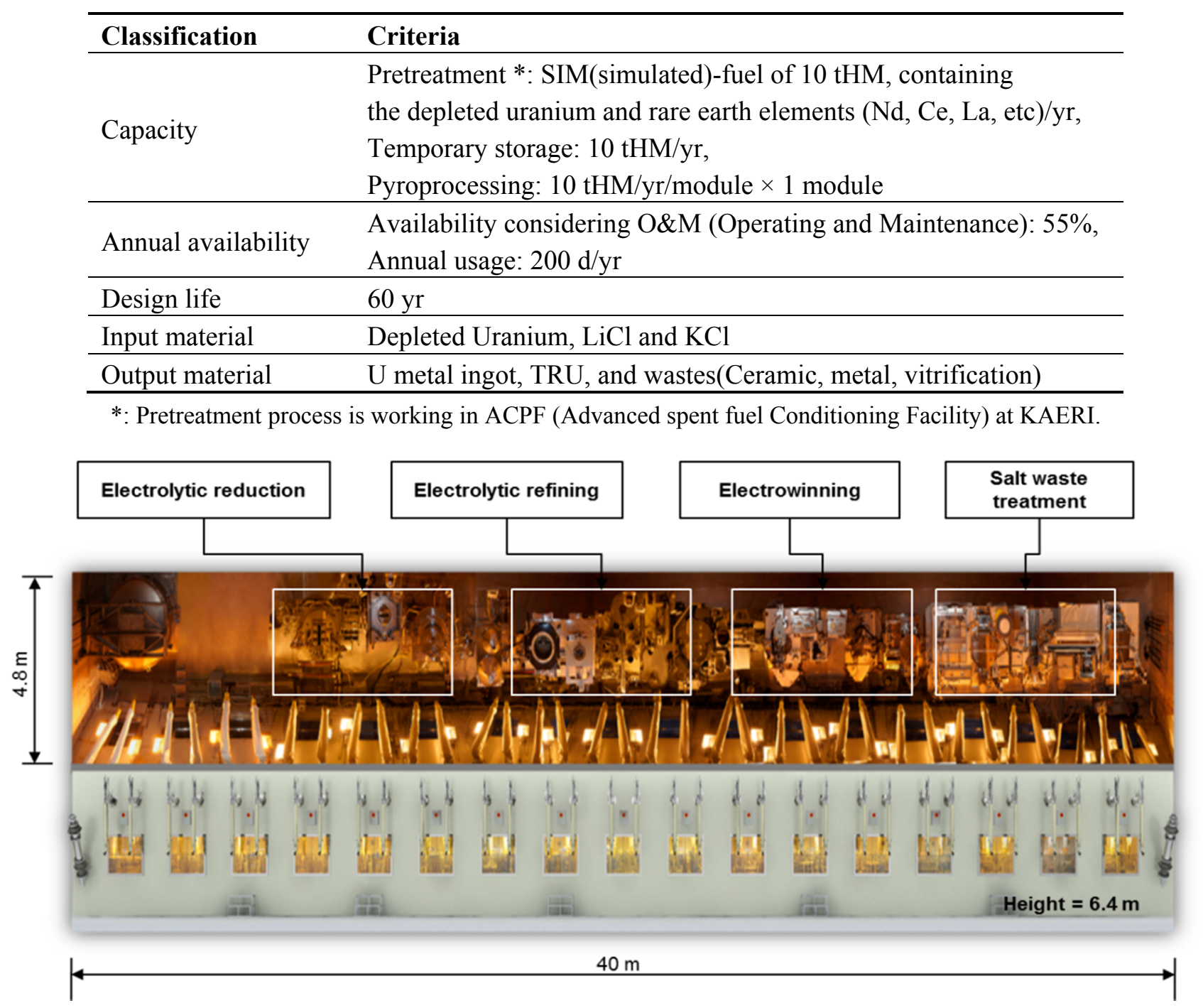

Figure 1. The sectional plane of the PyRoprocess Integrated inactive DEmonstration (PRIDE) facility.

PRIDE facility's Ar cell dimensions are $40 \mathrm{~m}, 4.8 \mathrm{~m}$, and $6.4 \mathrm{~m}$ in length, width, and height, respectively. The pretreatment process is implemented in an atmosphere of air. On the other hand, 
the pyroprocess is implemented in Ar cell with an atmosphere of argon gas where there exists virtually no oxygen/moisture (50 ppm or below) in order to suppress the oxidation reaction as required by the characteristics of the metal transformant [9]. The PRIDE is designed to operate at negative pressure of 10 to $200 \mathrm{mmAq}$ which are equivalent to $0.00096 \mathrm{~atm}$ and $0.01935 \mathrm{~atm}$ in magnitude, respectively.

The pyroprocess consists of unit-processes such as pretreatment, electrochemical reduction, electrorefining, electrowinning, removal of residual actinide, manufacturing of uranium and uranium-TRU ingots, and the recycling of salt-wastes. The core process of the pyroprocess facility is divided into four sectors as shown in Figure 2, including the pretreatment, electrochemical reduction, electrorefining and electrowinning.

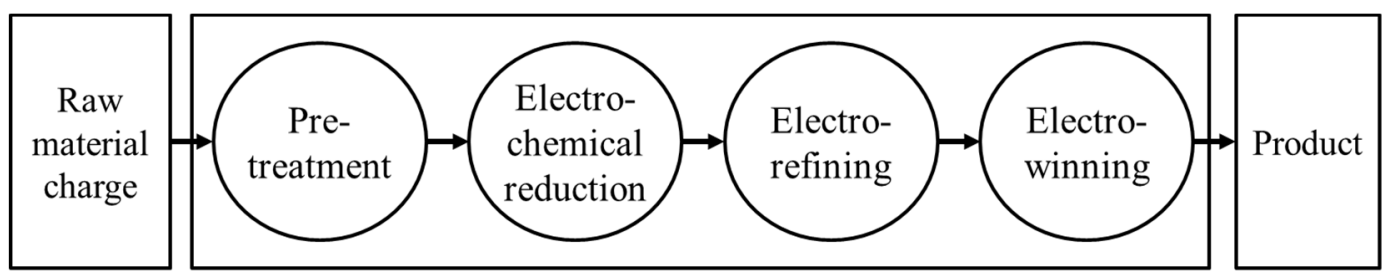

Work in process

Figure 2. The manufacturing unit process of pyroprocess.

The pretreatment process is a process in which the spent fuel that was emitted from light-water reactor power plants is received, dismantled, and cut, consisting of unit processes such as a dismantling of the assembly, fuel rod cutting, decladding and powdering, voloxidation, and waste disposal [9].

The electrochemical reduction process consists of a cathode consolidation process removing salt residues from the metal products generated from the pretreatment process, and converts the oxide materials into the metallic product in a $\mathrm{LiCl}-\mathrm{Li}_{2} \mathrm{O}$ molten salt at about $650{ }^{\circ} \mathrm{C}$. This chemical reaction uses the decomposition potential difference between $\mathrm{LiCl}, \mathrm{Li}_{2} \mathrm{O}$ and $\mathrm{UO}_{2}$. The potential of the electrolytic reduction process is determined where the $\mathrm{Li}_{2} \mathrm{O}$ electrolysis takes place without the decomposition of $\mathrm{LiCl}\left(-3.46 \mathrm{~V}<V_{\text {cell }}<-2.47 \mathrm{~V}\right)$. The metallic $\mathrm{Li}$ produced by the $\mathrm{Li}_{2} \mathrm{O}$ electrolysis reacts with $\mathrm{UO}_{2}$ within a cathode basket generating the reduced metal and $\mathrm{Li}_{2} \mathrm{O} . \mathrm{LiCl} 400 \mathrm{~kg} / \mathrm{year}$ are used as electrolyte solvent in the electrochemical reduction process.

The electrorefining process selectively collects high-purity uranium on the cathode from the reduced metal on the anode in the $\mathrm{LiCl}-\mathrm{KCl}$ eutectic salt at about $500{ }^{\circ} \mathrm{C}$. The salt distillation process recovers eutectic salt adhered to the uranium deposit.

The electrowinning system consists of an electrowinning process, a $\mathrm{Cd}$ (cadmium) distillation process and a TRU drawdown process. The electrowinning process recovers the residual uranium and TRU from the electro-refined $\mathrm{LiCl}-\mathrm{KCl}$ salt using $\mathrm{Cd}$. The recovered uranium and TRU moves to the liquid cadmium cathode (LCC) through the electrowinning process. The $\mathrm{Cd}$ distillation process performs to reuse cadmium from the liquid metal and TRU precipitates. Also the TRU drawdown process recovers a residual actinide from the waste salt. $\mathrm{LiCl} 270 \mathrm{~kg} /$ year and $\mathrm{KCl} 330 \mathrm{~kg} /$ year are used as electrolyte solvent in the electrowinning process. Figure 3 shows the flowchart of pyroprocessing.

The material flow values were calculated by using the ORIGEN-ARP code developed by Oak Ridge National Laboratory. Radioactive salt waste handling cost was classified as the cost of electrowinning. Accordingly, it is possible to calculate the unit cost of the overall pyroprocess when 
the unit costs of the four unit processes are estimated and added up, and it is possible to identify which process incurs the highest cost.

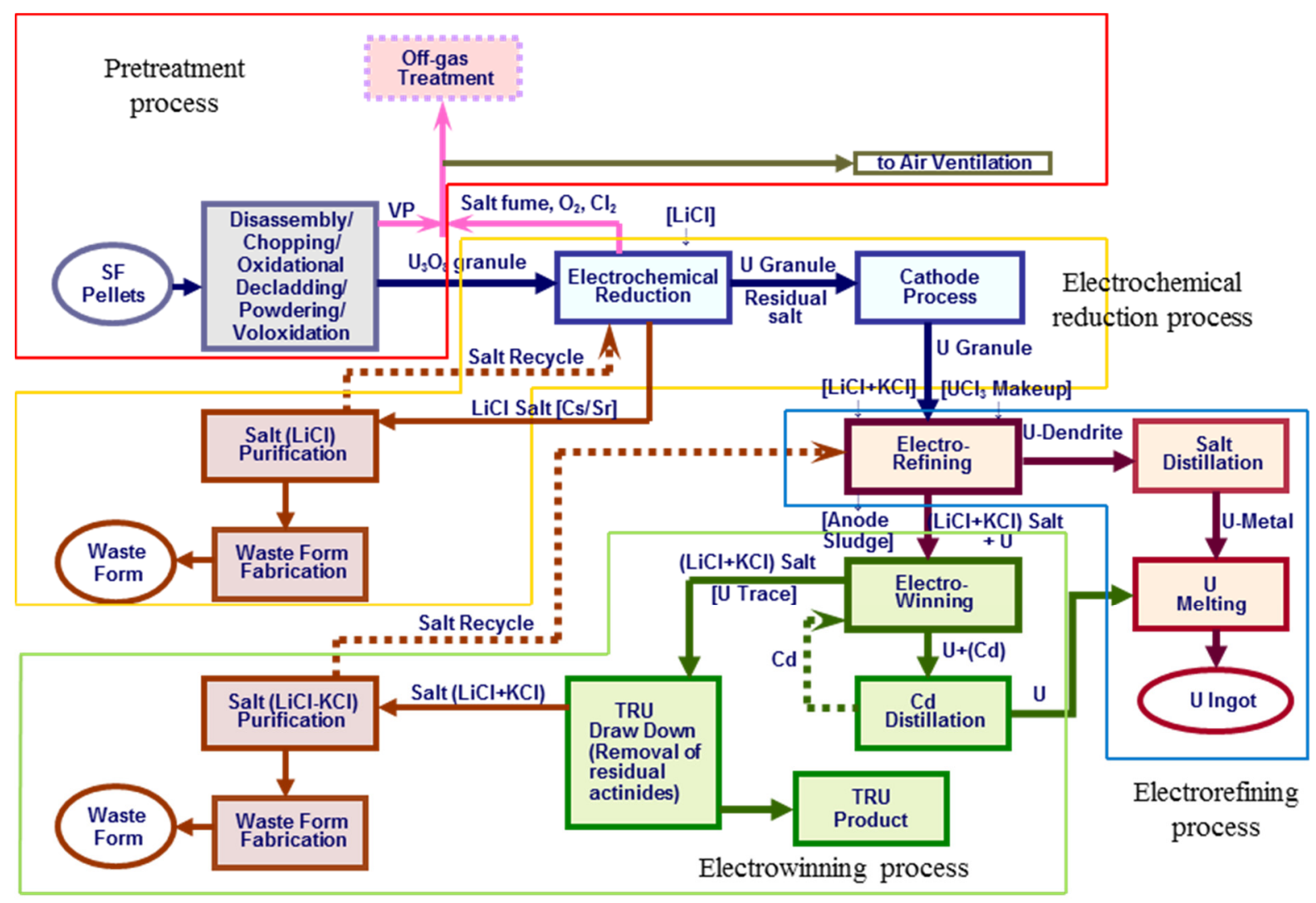

Figure 3. The pyroprocessing flowchart.

\subsubsection{Basics of the Process Costing Method}

It is necessary to set up the cost object first in order to calculate the unit cost [14], which is the pyroprocess facility's unit process. This paper set PRIDE as the cost object to calculate the pyroprocessing cost. This paper calculated the pyroprocessing unit cost by utilizing the information of the cost incurred from the PRIDE facility, and the cost accuracy is higher than that of the commercialization facility's estimated cost based on existing conceptual design. However, because the cost object is an engineering scale facility, it was assumed that the pyroprocessing cost is more expensive compared to that of a commercial facility because the PRIDE facility's size is significantly smaller than that of the commercial facility. Thus, it is not possible to factor in the economic gains resulting from the large capacity facility size to the PRIDE process unit cost.

The pyroprocessing cost presented by the existing studies was calculated using the engineering cost estimation method based on a conceptual design of a pyroprocessing facility [15]. In other words, the pyroprocessing unit cost was not discerned, and the costs that were consumed during the entire pyroprocess were estimated by dividing them into direct and indirect costs, and the sum of the capital investment cost, labor cost, expenses, and other costs was calculated as the total cost [16]. The direct costs and indirect costs are shown in Table 2.

In the engineering cost estimation, the indirect cost was calculated using the direct cost proportional method that relies on expert judgment [17], and it is seriously disadvantaged due to the uncertainty of 
the cost calculation result. In sum, a weakness of this type of cost calculation method is that it cannot accurately estimate the cost of each unit process.

Table 2. Direct costs and indirect costs.

\begin{tabular}{lll}
\hline Category & Capital Cost & O \& M Cost \\
\hline \multirow{3}{*}{ Direct cost } & Site preparation & Labor cost: wage of production workers \\
& Process systems (Equipment) & Equipment replacement \\
& Main process building & Materials (depleted uranium, LiCl and $\mathrm{KCl}$ ) \\
& Site support facilities & Transportation \\
\hline \multirow{2}{*}{ Indirect cost } & Conceptual/Final design & Materials (office supplies) \\
& Licenses & Labor cost: wage of facility inspector \\
& Engineering and construction management & Utilities-service(water, electricity) \\
& Startup and testing(Initial training) & Facilities-support (environment monitoring, security) \\
& & General and administrative costs (Tax, Insurance) \\
\hline
\end{tabular}

The process costing method, which can estimate the unit cost of each process, is an accounting method that can draw out the key cost drivers of pyroprocessing in a rational manner. It is a very effective cost calculation method that can mix the advantages of the engineering cost estimation method [18]. In particular, raw material costs, labor costs, and others used by this paper are real costs that are generated in the PRIDE facility. Thus, the accuracy level of the calculation result is very high compared to the engineering cost estimation method.

The process costing method is suitable for the process for producing considerable quantities of uranium ingot products [19]. Technology areas that can apply the process costing method include the chemical, oil refinery, and electronic industries [20].

The following is a simple example of production using two continuous processes shown to increase our understanding of the process costing method. Direct material cost and direct labor cost, which are used in the first process, and are levied to the Work-In-Process (WIP), accounts for the first process' production part, and the indirect manufacturing cost is distributed by the predetermined overhead rate [21]. When the first process is completed, the Work-In Process produced in the first process is delivered to the second process. Thus, the Work-In Process cost of the first process is replaced by the WIP accounts of the second process. Moreover, direct material, direct labor, and indirect manufacturing costs used during the second process are levied to the WIP of the second process [22]. Accordingly, it is possible to calculate the product cost since the product is completed when the production of the second process is completed. When this type of calculation method is applied to pyroprocessing, it is possible to calculate all costs required from the pretreatment of spent nuclear fuel to the electrowinning, which can be calculated by each unit process. Figure 4 shows the cost flow in pyroprocessing. The left side and right side in the T-account as shown in Figure 4 mean the debtor and the creditor, respectively. 


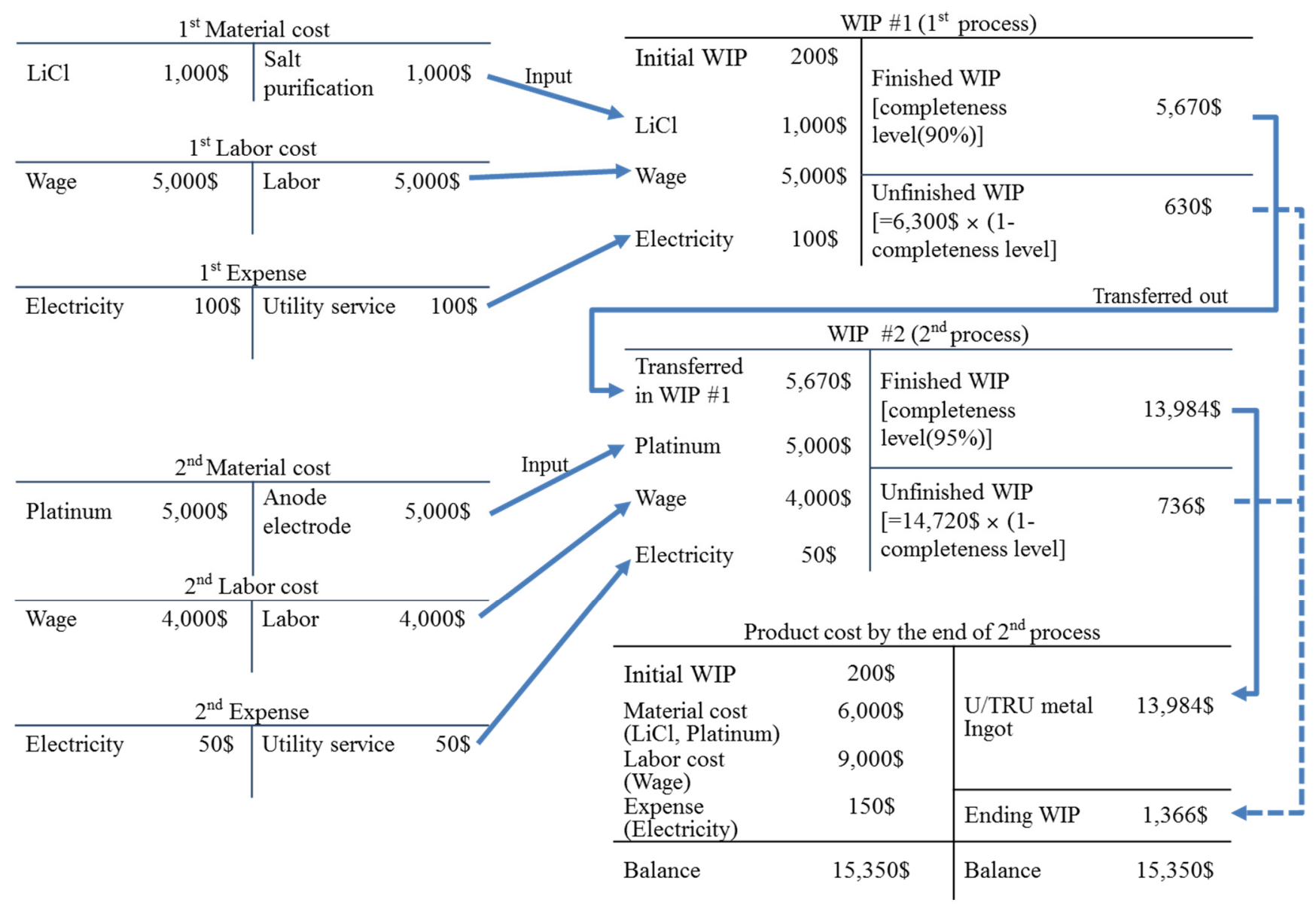

Figure 4. Flow of costs in pyroprocessing.

As for the process costing method, the cost in the Work-In-Process (WIP) accounts is replaced with the product accounts when the last unit process is completed. Moreover, the unit cost refers to the total average cost generated for one unit product, and the indirect manufacturing cost is distributed by referring to the manufacturing cost report. In other words, the WIP's completeness level is factored to calculate the equivalent units of product. Then, the finished product cost and ending WIP cost are calculated. The manufacturing cost report is a summary of the cost information including the production volume by each process, unit cost, finished product cost, and ending WIP cost by the process are included. Moreover, other information needed for a cost allocation is included as well. Equivalent units of product used in the process costing method act as a parameter that can measure the amount of work that is being carried out in the production activity presently as the core element of the process cost that factors into the cost calculation. In general, the manufacturing cost is comprised of the direct material, direct labor, and indirect manufacturing costs [22], which are the three cost elements, as shown in Figure 5. The capital cost belongs to the expenses through capitalizing as depreciation costs. In addition, the labor costs as well as the utility service costs belong to the conversion costs.

These costs are not input as a consistent ratio in the production process. In other words, direct material cost starts from the point when the production process starts. Meanwhile, direct labor and indirect manufacturing costs are input during the entire production process. Accordingly, when all of the direct material costs are input during the initial stage of the production, the initial WIP's 
completeness level is calculated as $100 \%$. However, the conversion activity is input during the entire production process. Thus, the conversion completeness level is determined by the processing activity's completeness level. For example, when the conversion activity completed is $60 \%$, the product's completeness level is $60 \%$. When equivalent units of product are calculated by applying this concept, the WIP is calculated as the equivalent units of product of the 60 units by factoring in the $60 \%$ completeness level when 100 units are produced in terms of the production process. Thus, the process costing method calculates the cost by converting the direct material cost and conversion cost into the equivalent units of product instead of calculating the cost with the number of input units.

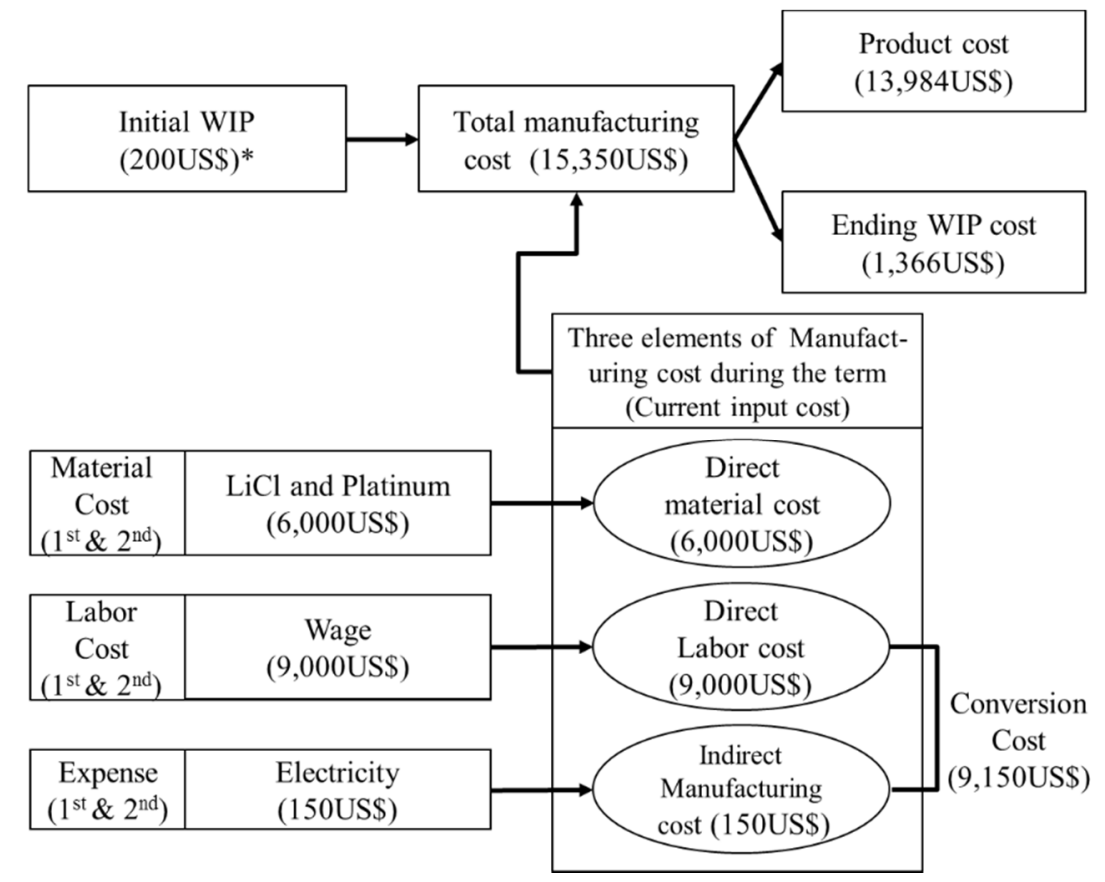

Figure 5. The three element of manufacturing cost $(*$ : US\$ in parenthesis indicate the costs in Figure 4).

A flow chart of the process costing method is shown in Figure 6.

\begin{tabular}{|c|c|}
\hline 1 Step & Material flow calculation(completed initial WIP and completed current input) \\
\hline 2 Step & Calculation of the equivalent units of product by cost elements \\
\hline 3 Step & $\begin{array}{c}\text { Unit cost calculation by cost elements } \\
\text { (current input cost divided by the equivalent units of product excluding the initial } \\
\text { WIP cost) }\end{array}$ \\
\hline & $\begin{array}{c}\text { Calculation of product cost and ending WIP cost } \\
\text { (product cost= Initial WIP cost + the equivalent units of product X unit cost, } \\
\text { Ending WIP cost }=\text { the equivalent units of product of ending WIP X unit cost) }\end{array}$ \\
\hline 5 Step & Pyroprocess unit cost calculation by the sum of all process costs \\
\hline
\end{tabular}

Figure 6. The procedure of a process costing method using First-In First-Out method. 
The process cost can be classified into the finished product cost that already underwent the product process and the WIP cost (ending WIP) that is still in product, as shown in Figure 7. Such costs are used to calculate the unit process cost that is incurred during the continuous process. Accordingly, the pyroprocess cost is classified into the direct material and conversion costs, as shown in Equation (1) [23]. The conversion cost is classified into the labor and indirect costs once again, as shown in Equation (2) [23]:

$$
T C=\sum_{t} \sum_{i} M c_{i, t}+\sum_{t} \sum_{j} C c_{j, t}
$$

where $T C=$ total cost of the pyroprocess (unit: US\$), $t=$ time (from the beginning of the year by year's end), $M c_{i, t}=$ the direct material cost (including WIP) of the $i$-th process at time $t$ (unit: US\$), and $C c_{j, t}=$ the conversion cost (including the manufacturing cost during the term) of the $j$-th process at time $t$ (unit: US\$):

$$
\sum_{t} \sum_{j} C c_{j, t}=\sum_{t} \sum_{j} L c_{j, t}+\sum_{t} \sum_{j} I c_{j, t}
$$

where $L c_{j, t}=$ the direct labor cost of the $j$-th process at time $t$ (unit: US $\$$ ), and $I c_{j, t}=$ the indirect manufacturing cost of the $j$-th process at time $t$ (unit: US\$).

\begin{tabular}{c|c}
\hline Debtor & Creditor \\
\hline Quantity of initial WIP & Quantity of the product \\
\hline Quantity of current input & Quantity of ending WIP \\
\end{tabular}

Figure 7. T-account for the quantity of product.

Thus, the initial WIP cost, including the raw material cost, can be calculated by using both the weighted average method and First-In First-Out method according to the process costing method. As shown Figure 8, the foremost characteristic of the weighted average method is that it does not distinguish the initial WIP cost and current term's input cost. In other words, the initial WIP cost and current term's input cost are subjected to the weighted average to levy onto the debit accounts, and the finished product cost and ending WIP cost are input into the credit accounts [19]. Accordingly, when the calculation of the material flow as the first stage to calculate the pyroprocess unit cost is expressed as the T-account, it is possible to be expressed, as shown in Figure 7. As shown Figure 9, meanwhile, in the First-In, First-Out method, the initial WIP cost is allocated to the finished product cost only. The cost of current term is allocated into the finished product cost and ending WIP cost.

Table 3 summarizes difference between weighed average method and First-In, First-Out method.

In the end, the First-In, First-Out method can estimate the unit process cost with the current term's product performance. The cost calculation process is complicated compared with the weighted average method. On the other hand, the accuracy level of the cost estimation is high. Table 4 shows the allocation ratios in each process. 


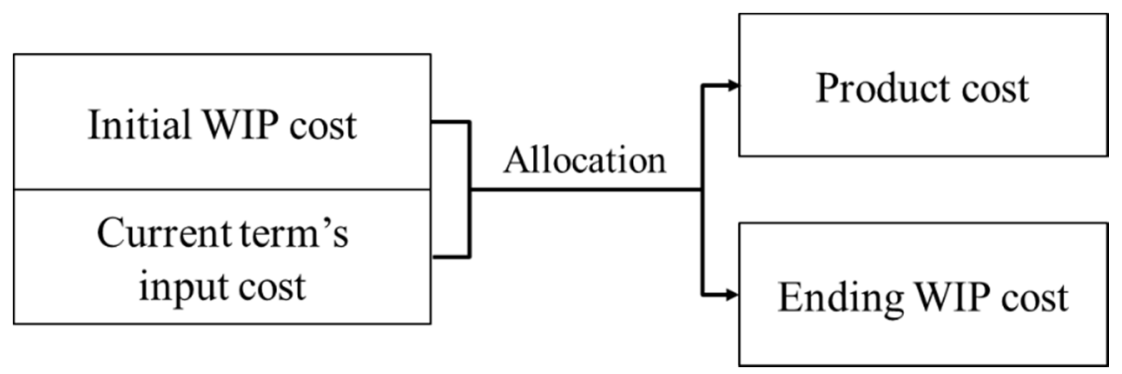

Figure 8. The cost allocation of weighted-average method.

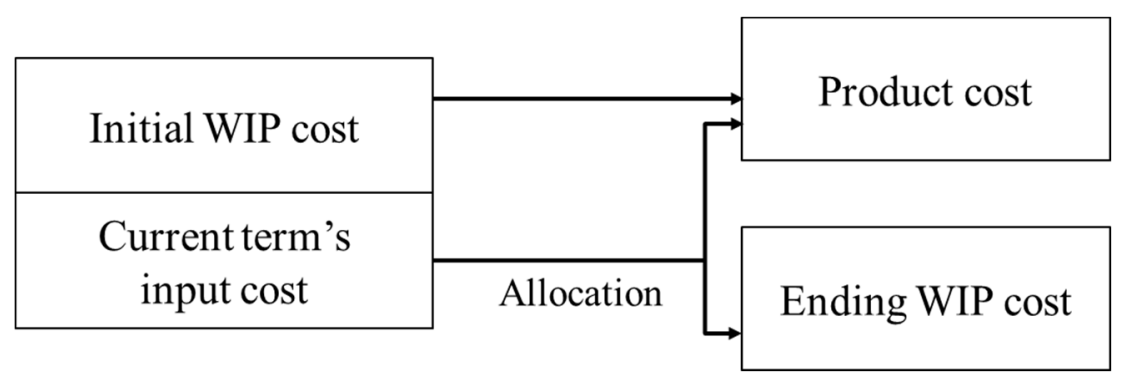

Figure 9. The cost allocation of First-In First-Out method.

Table 3. The difference between weighted average method and First-In, First-Out method.

\begin{tabular}{ll}
\hline Weighted Average Method & First-In, First-Out Method \\
\hline $\begin{array}{l}\text { Assumes that the initial WIP was input during the } \\
\text { current term for the calculation of the equivalent units of } \\
\text { product and treats it the same way as the volume input } \\
\text { during the current term }\end{array}$ & $\begin{array}{l}\text { - Initial WIP and volume input during the current term are } \\
\text { distinguished for the calculation of the equivalent units } \\
\text { of product }\end{array}$ \\
\hline $\begin{array}{l}\text { - Amount subject to cost calculation is the sum of the } \\
\text { initial WIP cost and cost input in the current term }\end{array}$ & $\begin{array}{l}\text { - Initial WIP cost is a part of the finished product cost and cost } \\
\text { input in the current term is distinguished into finished } \\
\text { products and ending WIP }\end{array}$ \\
$\begin{array}{ll}\text { - Unit cost for the equivalent units of product includes } \\
\text { cost of the previous term }\end{array}$ & $\begin{array}{l}\text { Unit cost for the equivalent units of product is comprised } \\
\text { merely of the cost input in the current term }\end{array}$ \\
$\begin{array}{l}\text { The finished product cost is the amount that multiplied } \\
\text { of the equivalent units of product }\end{array}$ & $\begin{array}{l}\text { The finished product cost is comprised of the cost consumed } \\
\text { formished products by factoring in the product's }\end{array}$ \\
\hline
\end{tabular}

Table 4. Allocation ratios (completeness level) in each process.

\begin{tabular}{ccc}
\hline \multirow{2}{*}{ Process Name } & \multicolumn{2}{c}{ Allocation Ratios: Completeness Level [unit: \%] } \\
\cline { 2 - 3 } & Product Cost & Ending WIP Cost \\
\hline Pretreatment & 93 & 7 \\
Electrochemical reduction & 94 & 6 \\
Electrorefining & 94 & 6 \\
Electrowinning & 95 & 5 \\
\hline
\end{tabular}




\subsection{Process Costing Method Based on First-In, First-Out}

A uranium ingot, which is the product produced in the pyroprocess, is produced through four processes, and the cost needs to be replaced among the processes as the WIP moves through the steps. In other words, the cost that is replaced with the next process is called the transferred-in cost. Because this is processed by obtaining an input at the point when the process starts, it is treated like a direct material cost since it acts like some kind of input item from the follow-up process' perspective. Accordingly, the follow-up process' cost calculation can be carried out with the transferred-in cost that is replaced from the previous process and the cost that is input additionally by the cost element. In other words, the manufacturing cost can be calculated by dividing into the direct material and conversion costs.

First-In, First-Out, which this research considered to be adequate for the calculation of the cost for pyroprocessing, assumes that the volume that was input first gets completed first [19]. The initial WIP's equivalent units of product can calculate the initial WIP's completeness level, as shown in Equation (3). Ending the WIP's equivalent units of product can be calculated by using the ending WIP's completeness level as shown in Equation (4). Accordingly, the equivalent units of product for the entire volume can be expressed as shown in Equation (5):

$$
Q_{j}^{F W I P}=I_{j, t}^{W I P} \times D O C_{j}^{I}
$$

where $Q_{j}^{\text {FIP }}=$ quantity of the current completed WIP for the $j$-th process (unit: $\mathrm{kg}$ ), $I_{j, t}^{W I P}=$ the initial WIP for the $j$-th process at time $t$ (unit: $\mathrm{kg}$ ), and $D O C_{j}^{I}=$ the degree of the initial WIP completion (unit: \%):

$$
Q_{j}^{E W I P}=W I P_{j, t}^{E n d i n g} \times D O C_{j}^{E}
$$

where $Q_{j}^{E W I P}=$ quantity of the ending WIP for the $j$-th process (unit: $\mathrm{kg}$ ), WIP ${ }_{j, t}^{\text {Ending }}=$ the uncompleted ending WIP for the $j$-th process at time $t$ (unit: $\mathrm{kg}$ ), and $D O C_{j}^{E}=$ the degree of ending WIP completion (unit: \%):

$$
E U P_{j}=Q_{j}^{I W I P}+Q_{j}^{F W I P}+Q_{j}^{E W I P}
$$

where $E U P_{j}=$ the equivalent units of product for the $j$-th process (unit: $\mathrm{kg}$ ), $Q_{j}^{I W I P}=$ quantity of the initial WIP for the $j$-th process (unit: $\mathrm{kg}$ ).

The initial assumption for the cost flow is unnecessary if there is no initial WIP in the process costing method. Thus, the results of the weighted average method and First-In, First-Out method match. When the initial WIP exists, some difference in the finished product cost and cost for the WIP for the weighted average method and First-In, First-Out results.

The cost for the First-In, First-Out method is comprised of raw materials and conversion costs. The unit cost for the current term is calculated by dividing the cost input in the current term by the equivalent units of product. At this time, the cost related to the initial WIP is assumed to be input already. Thus, the initial WIP cost is excluded. It is possible to calculate the unit cost of raw material when the raw material cost is divided by the equivalent units of product, as shown in Equation (6). 
In addition, it is possible to calculate the unit cost of conversion if the conversion cost is divided by the equivalent units of product, as shown in Equation (7):

$$
U C_{E U P}^{M A}=\frac{\sum_{t} A M C_{j, t}}{\sum_{t} E U P_{j, t}}
$$

where $U C_{E U P}^{M A}=$ the unit cost of the equivalent units of product regarding the raw material cost (unit: US\$ $/ \mathrm{kg}$ ), $A M C_{j, t}=$ accrued raw material cost in the $j$-th process at time $t$ (unit: US\$ $/ \mathrm{kg}$ ), and $E U P_{j, t}=$ equivalent units of product in the $j$-th process at time $t$ (unit: $\mathrm{kg}$ ):

$$
U C_{E U P}^{C C}=\frac{\sum_{t} A C C_{j, t}}{\sum_{t} E U P_{j, t}}
$$

where $U C_{E U P}^{C C}=$ the unit cost of the equivalent units of product regarding the conversion cost (unit: US\$/kg), and $A C C_{j, t}=$ accrued conversion cost in the $j$-th process at time $t$ (unit: US\$/kg).

The First-In, First-Out method calculates the finished product cost and WIP's cost by distinguishing them into two stages. In other words, there is no need to input additional material in the current term since the direct material cost for the initial WIP was already input in its entirety. Instead, a calculation is made by assuming that the completion took place by processing additionally in the current term up to the remaining level of processing by factoring in the completeness level (\%). Accordingly, Equation (8) is utilized to calculate the unit process cost incurred during the current term regarding the initial WIP and the completion of the initial WIP. In other words, the sum of the raw material cost and processing cost is calculated to calculate the finished product cost. Lastly, the ending WIP cost is calculated with the sum of the WIP's raw material and conversion costs, as shown in Equation (9):

$$
M C_{j}=\sum_{t} C_{j, t}^{I W I P}+\sum_{t} Q F I W I P_{j, t} \times U C_{E U P}+\sum_{t} Q F C P_{j, t}^{M C} \times U C_{E U P}^{M A}+\sum_{t} Q F C P_{j, t}^{C C} \times U C_{E U P}^{C C}
$$

where $M C_{j}=$ manufacturing cost (unit: US\$), $C_{j, t}^{I W I P}=$ the cost of IWIP (initial WIP) for the $j$-th process at time $t$ (unit: US\$), QFIWIP ${ }_{j, t}=$ quantity of the finished IWIP for the $j$-th process at time $t$ (unit: $\mathrm{kg}$ ), $U C_{E U P}=$ unit cost of the equivalent units of product (unit: $\mathrm{US} \$ / \mathrm{kg}$ ), $Q F C P_{j, t}^{M C}=$ quantity of the finished current product regarding the raw material cost for the $j$-th process at time $t$ (unit: $\mathrm{kg}$ ), and $Q F C P_{j, t}^{C C}=$ quantity of the finished current product regarding the conversion cost for the $j$-th process at time $t$ (unit: $\mathrm{kg}$ ):

$$
C_{j}^{E W I P}=\sum_{t} Q E W I P_{j, t}^{M A} \times U C_{E U P}^{M A}+\sum_{t} Q E W I P_{j, t}^{C C} \times U C_{E U P}^{C C}
$$

where $C_{j}^{E W I P}=$ the cost of the ending WIP for the $j$-th process (unit: US\$), $Q E W I P_{j, t}^{M A}=$ quantity of the ending WIP regarding the raw material cost for the $j$-th process at time $t$ (unit: $\mathrm{kg}$ ), and $Q E W I P_{j, t}^{C C}=$ quantity of the ending WIP regarding the conversion cost for the $j$-th process at time $t$ (unit: $\mathrm{kg}$ ). 


\subsection{Input Data}

The spent fuel is converted into metal during the electrochemical reduction process, uranium is recovered in the electrorefining process, and the remaining uranium and TRU are recovered in an ingot state during the electrowinning process.

The recovered surplus uranium is either recycled or disposed of as low-level waste, and U-TRU ingots are used as a raw material for SFR nuclear fuel.

Figure 10 shows the material flow and mass balance for the treatment of 10 MTHM (Metric Ton of Heavy Metal) of pre-treated nuclear spent fuel with 4.5 wt \% of U-235, 55,000 MWD/MTU (MegaWatt Day/Metric Ton of Uranium), and 10-year cooling. As shown in Figure 10, approximately $9054 \mathrm{kgHM}$ and $208 \mathrm{kgHM}$ of uranium and U/TRU metal can be recovered, respectively.

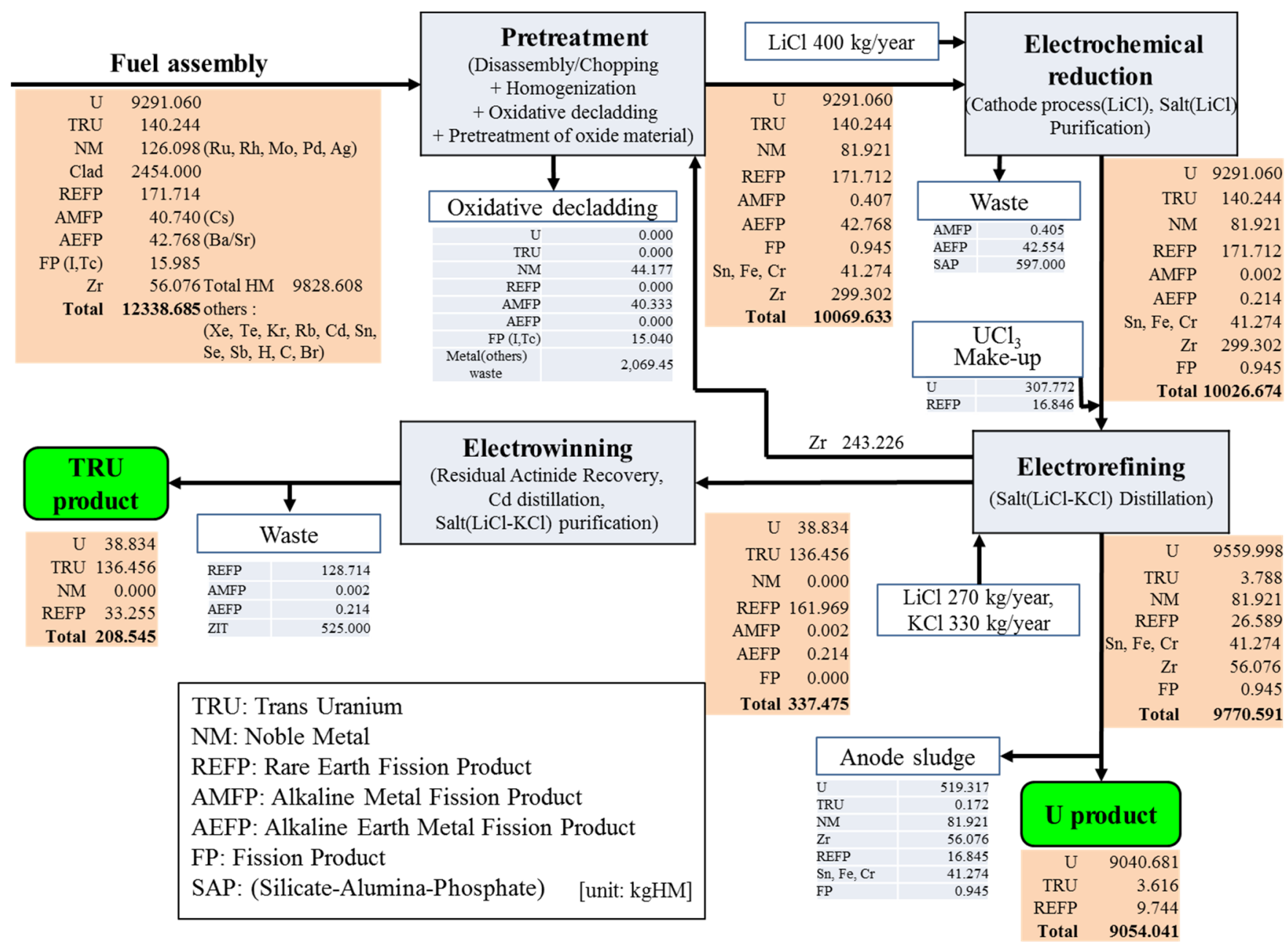

Figure 10. Material flow and mass balance.

In addition, the main material costs are shown in Table 5. To construct the PRIDE facility, a capital cost of 33,000k US\$ was invested between 2007 and 2012 and the equipment test was carried out from 2012 to 2013. The details are shown in Table 6. From Table 6, the capital unit cost using Equation (10) was estimated to be $145 \mathrm{US} \$ / \mathrm{kgU}-\mathrm{TRU}$ considering interest during depreciation periods over 60 years. Tables 7 and 8 show labor costs and utility service costs, respectively: 


$$
U C_{\text {Cap }}=\frac{\sum_{t} \operatorname{PRIN}_{t} \times(1+r)^{T 1-T 0}}{\frac{\sum_{t} Q P_{t}}{(1+d)^{T 1-T 0}}}
$$

where $U C_{C a p}=$ capital unit cost(unit: US\$ $/ \mathrm{kg}$ ), $P R I N_{t}=$ principal at time $t$ (unit: US\$), $r=$ the interest rate of Korean national bond with the maturity of 10 years $=3.8 \%, T 1=$ current year, $T 0=$ base year (at the end of 2014), $Q P_{t}=$ the quantity of product at time $t$ (unit: $\mathrm{kgHM}(\mathrm{Heavy}$ Metal)), $d=$ discount rate $=3 \%$.

Table 5. Main material costs.

\begin{tabular}{|c|c|c|c|c|}
\hline Process Name & Chemical & $\begin{array}{c}\text { Amount } \\
(\mathrm{kg})\end{array}$ & $\begin{array}{l}\text { Unit Cost } \\
\text { (US\$/kg) }\end{array}$ & $\begin{array}{c}\text { Total Cost } \\
\text { (US\$) }\end{array}$ \\
\hline \multirow{3}{*}{ Pretreatment } & $\mathrm{O}_{2}$ & 353.8 & 11 & 4065 \\
\hline & $\mathrm{Ar}$ & 576.4 & 3 & 2006 \\
\hline & $\mathrm{H}_{2}-\mathrm{Ar}$ & 7417.6 & 12 & 85,718 \\
\hline \multirow{3}{*}{ Electrochemical reduction } & $\mathrm{LiCl}$ & 1449.5 & 100 & 144,950 \\
\hline & $\mathrm{Li}_{2} \mathrm{O}$ & 36.3 & 3656 & 132,723 \\
\hline & $\mathrm{Pt}$ & 9.2 & 54,000 & 496,852 \\
\hline \multirow{2}{*}{ Electrorefining } & $\mathrm{LiCl}-\mathrm{KCl}$ & 908.0 & 128 & 115,860 \\
\hline & $\mathrm{UCl}_{3}$ & 847.7 & 183 & 154,858 \\
\hline \multirow{8}{*}{ Electrowinning } & $\mathrm{Cd}$ & 282.5 & 121 & 34,181 \\
\hline & SAP (Silicate-Alumina-Phosphate) & 292.2 & 270 & 78,906 \\
\hline & glass frit & 116.9 & 30 & 3507 \\
\hline & $\mathrm{Li}_{3} \mathrm{PO}_{4}$ & 48.6 & 6450 & 313,498 \\
\hline & $\mathrm{K}_{3} \mathrm{PO}_{4}$ & 61.5 & 260 & 15,967 \\
\hline & ZIT (Zinc Titanate) & 399.5 & 200 & 79,903 \\
\hline & $\mathrm{CdCl}_{2}$ & 10.9 & 2475 & 26,892 \\
\hline & & & \multicolumn{2}{|c|}{ (Throughput: $10 \mathrm{t}$ SIM-fuel/year } \\
\hline
\end{tabular}

Table 6. Capital cost [unit: US\$].

\begin{tabular}{cccc}
\hline Year & $\begin{array}{c}\text { Investment } \\
\text { (Overnight Cost) }\end{array}$ & $\begin{array}{c}\text { IDC } \\
\text { (Interest During Construction) }\end{array}$ & $\begin{array}{c}\text { Cost } \\
\text { (Base Year = 2014) }\end{array}$ \\
\hline 2007 & $3,300,000$ & 984,453 & $4,284,453$ \\
2008 & $8,580,000$ & $2,151,771$ & $10,731,771$ \\
2009 & $8,910,000$ & $1,826,543$ & $10,736,543$ \\
2010 & $7,590,000$ & $1,221,122$ & $8,811,122$ \\
2011 & $3,300,000$ & 390,677 & $3,690,677$ \\
2012 & $1,320,000$ & 102,226 & $1,422,226$ \\
Total & $33,000,000$ & $6,676,792$ & $39,676,792$ \\
\hline
\end{tabular}


Table 7. Labor costs [unit: 1,000US\$/year].

\begin{tabular}{ccccc}
\hline Process Name & Duties & Man-Year & Unit Cost & Labor Cost \\
\hline \multirow{4}{*}{ Pretreatment } & Manager & 1 & 131 & 131 \\
& Process Engineers & 4 & 73 & 290 \\
& Mechanical Engineers & 3 & 73 & 218 \\
& Chemical Engineer & 2 & 73 & 145 \\
& sub-total & 10 & - & 783 \\
\hline \multirow{5}{*}{ Electrochemical reduction } & Manager & 1 & 131 & 131 \\
& Process Engineers & 4 & 73 & 290 \\
& Mechanical Engineers & 3 & 73 & 218 \\
& Chemical Engineer & 7 & 73 & 508 \\
& sub-total & 15 & - & 1146 \\
\hline \multirow{5}{*}{ Electrorefining } & Manager & 1 & 131 & 131 \\
& Process Engineers & 4 & 73 & 290 \\
& Mechanical Engineers & 3 & 73 & 218 \\
& Chemical Engineer & 8 & 73 & 580 \\
& sub-total & 16 & - & 1218 \\
\hline \multirow{5}{*}{ Eletrowinning } & Manager & 1 & 131 & 131 \\
& Process Engineers & 3 & 73 & 218 \\
& Mechanical Engineers & 3 & 73 & 218 \\
& Chemical Engineer & 7 & 73 & 508 \\
& sub-total & 14 & - & 1073 \\
\hline \multirow{5}{*}{ Total Staffing } & 55 & & 4220 \\
\hline \multirow{5}{*}{} & & &
\end{tabular}

Table 8. Utility service costs (expense).

\begin{tabular}{cc}
\hline Process Name & Utility Service Costs (Unit: US\$/year) \\
\hline Pretreatment & $35,558.0$ \\
Electrochemical reduction & $42,847.0$ \\
Electrorefining & $16,147.5$ \\
Electrowinning & $24,254.5$ \\
Total & $118,807.0$ \\
\hline
\end{tabular}

Equation (10) shows the calculation method of the capital unit cost. The cost was calculated in US\$ at the end of the year 2014 cost level.

Figures 11 and 12 represent the amount of input and output materials. The input and out materials mean SIM fuel and the recovered nuclides, respectively. It was assumed that about $10 \mathrm{tHM} /$ year could be treated in PRIDE facility and the lifetime is 60 years. The reason for the fluctuation of the input material is the gap between the transferred in materials and the initial WIP. The gap arises from differences in the processing time of equipment. 


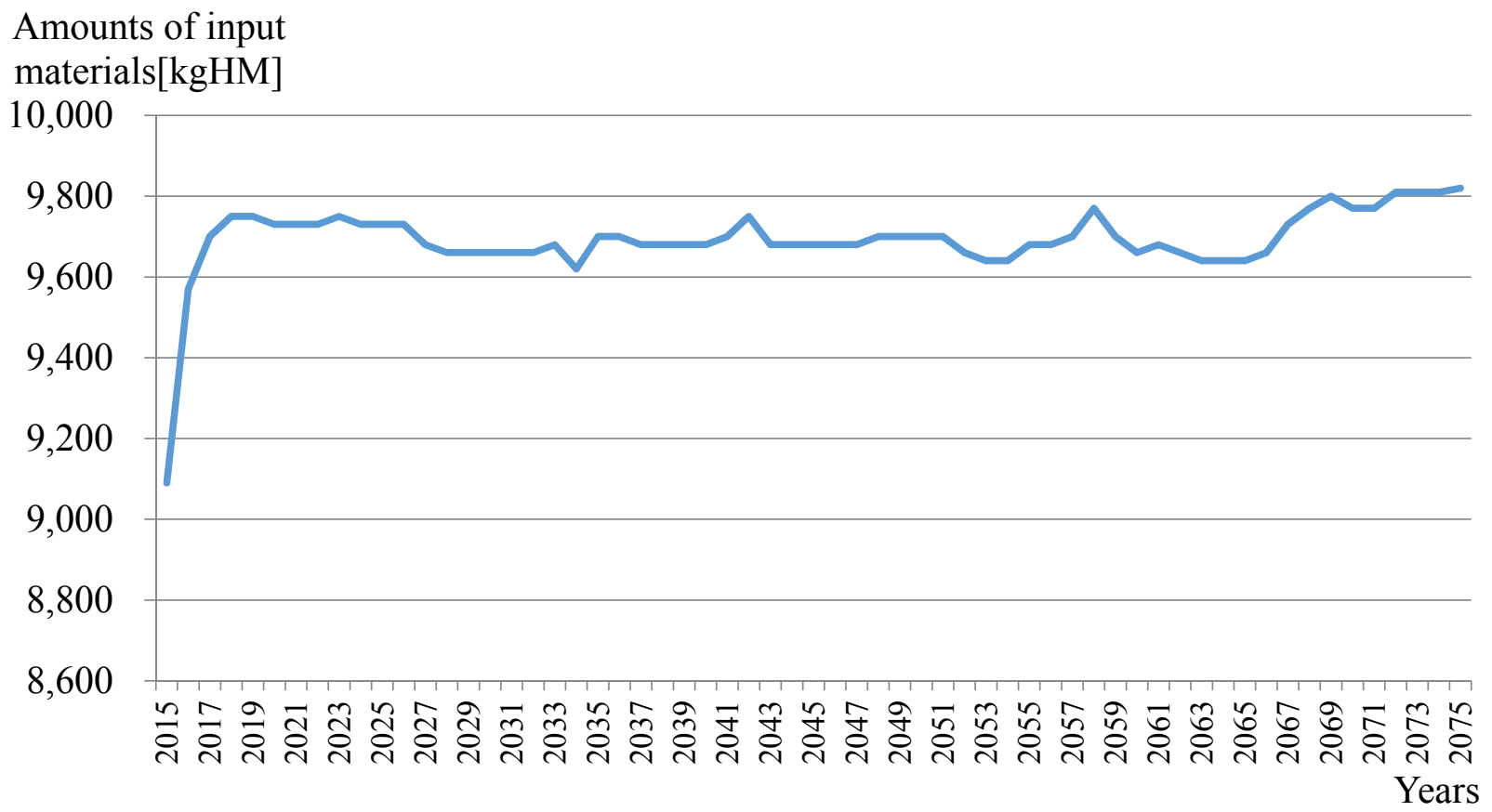

Figure 11. Amounts of input materials.

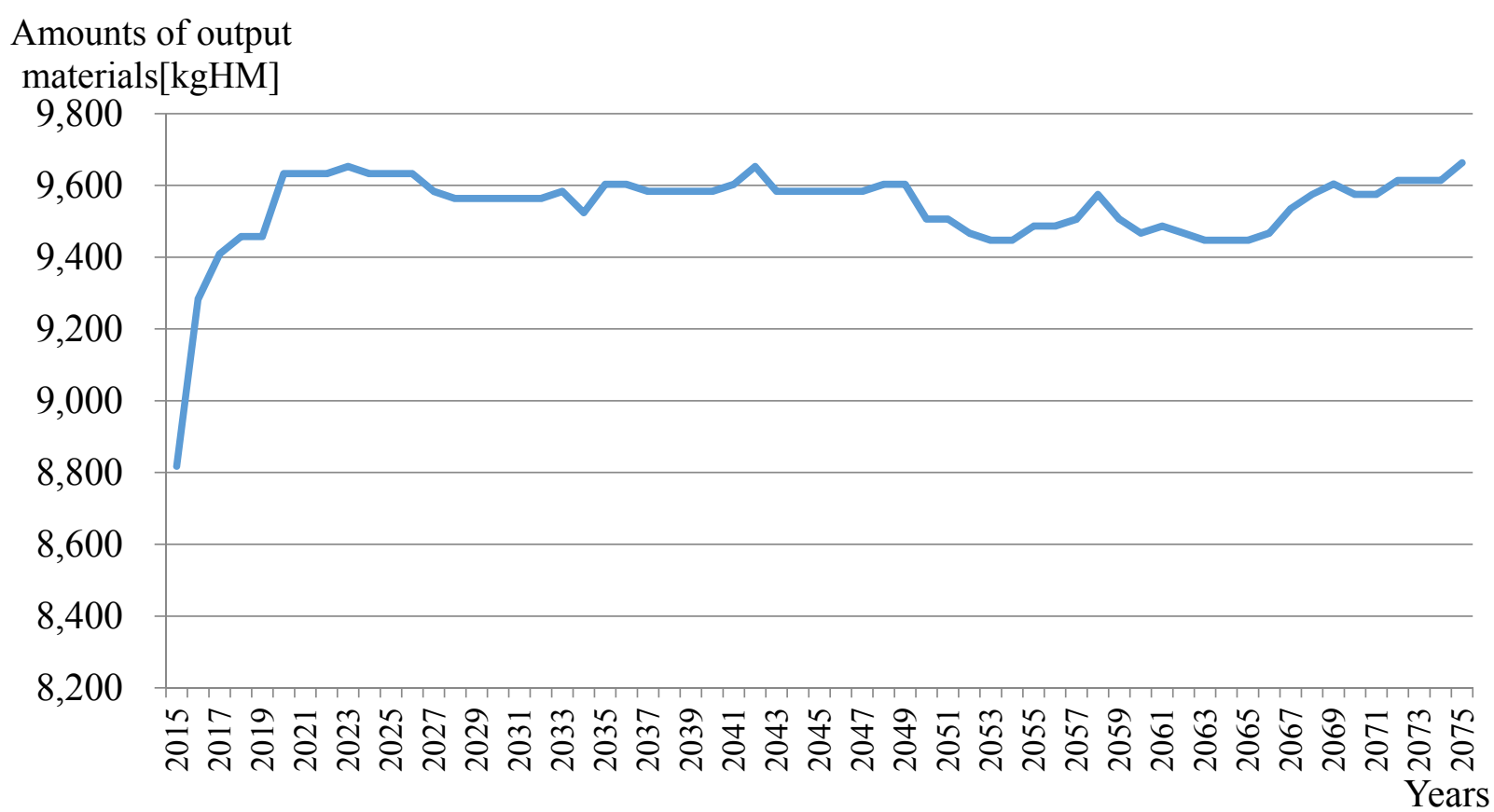

Figure 12. Amounts of output materials.

\subsection{Facility Decommissioning and Disposal Cost}

The commercial facility uses spent nuclear fuel as a raw material. Accordingly, when the facility's design lifetime ends, the facility and machine equipment are decommissioned [24], and the radio-activate machine equipment parts are disposed of as radioactive waste. The waste should be classified as low-level, intermediate-level, and high-level radioactive waste in accordance with the Korean Radioactive Waste Law [12]. Thus, the engineering cost estimation method assumes $1 \%$ of the 
direct cost that is input every year as the decommissioning cost [25]. However, these costs were not considered in this study since it was estimated that they will not exert a significant effect on the pyroprocess unit cost. According to the cost estimation results of Nuclear Energy Agency (NEA), the decommissioning cost is estimated to be about $0.3 \%$ of the nuclear electricity generation cost [12].

\subsection{Spoilage Accounting Management}

A defective product that is subjected to waste disposal is called a spoilage unit. The defective product means the manufactured uranium ingot contained a lot of impurities. However, this paper does not consider the spoilage unit in the cost estimation by factoring in the fact that the pyroprocess' uranium recovery rate is at least $95 \%$.

\section{Results and Discussion}

\section{Cost Estimation Results}

It was assumed that there is no initial WIP of the pretreatment for calculating the material flow among the unit processes. The completeness level of the initial WIP was assumed by referring to the actual PRIDE facility's operation performance, from the electrochemical reduction to electrowinning. Table 9 shows the material flow that was subjected to each unit process' weighted average and volume (throughput) processed by each unit process, from pretreatment to electrowinning.

Table 9. Material flows and product in each process (annual basis).

\begin{tabular}{ccccc}
\hline Category & Pretreatment & $\begin{array}{c}\text { Electrochemical } \\
\text { Reduction }\end{array}$ & Electrorefining & Electrowining \\
\hline Initial WIP & 0 & 2000 & 1000 & 1000 \\
Current input & 10,000 & 8000 & 9000 & 9000 \\
Completed current input & 8000 & 7000 & 8000 & 9000 \\
Ending WIP ${ }^{1)}$ & 2000 & 1000 & 1000 & 0 \\
Product $^{2)}$ & 8000 & 9000 & 9000 & 10,000 \\
\hline
\end{tabular}

1) $($ Current input $)-($ Completed current input $)=\left(\right.$ Ending WIP) [unit: kgU-TRU]; ${ }^{2)}$ (Initial WIP $)+$ (Completed current input $)=($ Product $)$.

The amounts of (Ending WIP) and (Product) is transferred to (Initial WIP) and (Current Input) in the next process. Each unit process' handling speed is different in actuality from the facility's operation aspect. Thus, the WIP storage facility, which has the role of a so-called buffer that can store WIP temporarily before the WIP gets transferred to the next process is needed. Accordingly, there is a need to develop a process system that can handle the WIP most effectively through a process simulation [26].

Table 10 shows the results of calculating the raw material and conversion costs (labor cost included) by each unit process. The cost data of Table 10 were used to calculate the process unit cost by each unit process. The unit costs of the pyroprocess and cost share were calculated. The unit cost of the pretreatment process was calculated as $195 \mathrm{US} \$ / \mathrm{kgU}-\mathrm{TRU}$, and the cost share was $20.46 \%$, as shown in Table 11. The unit cost of the electrochemical reduction process that requires the most 
cost was calculated as $310 \mathrm{US} \$ \mathrm{kgU}-\mathrm{TRU}$, manifesting a cost share of $32.63 \%$. Electrorefining and electrowinning processes were calculated as $22.65 \%$ and $24.26 \%$, demonstrating that the costs are very similar. The reason that it takes up the most cost during the electrochemical reduction process is because the raw material cost of platinum, which is used as an anode electrode, is very expensive at 54,000 US $\$ / \mathrm{kg}$ as shown in Table 5. Thus, platinum's raw material cost was the key cost driver of the electrochemical reduction process. Moreover, the raw material cost of $\mathrm{Li}_{3} \mathrm{PO}_{4}$ for the $\mathrm{LiCl}-\mathrm{KCl}$ purification process is $6450 \mathrm{US} \$ / \mathrm{kg}$. This expensive material was the cost driver of the electrowinning process. The ratios of material costs of $\mathrm{Pt}$ and $\mathrm{Li}_{3} \mathrm{PO}_{4}$ to the unit cost of each process were $20 \%$ and $14 \%$, respectively.

Table 10. Raw material costs and conversion costs (annual basis).

\begin{tabular}{|c|c|c|c|}
\hline \multirow{2}{*}{$\begin{array}{c}\text { Category } \\
\text { Process Name }\end{array}$} & \multicolumn{2}{|c|}{ Process Cost } & \multirow{2}{*}{$\begin{array}{c}\text { Cost } \\
\text { [US\$/year] }\end{array}$} \\
\hline & $\begin{array}{c}\text { Raw Material Cost } \\
\text { [US\$/year] }\end{array}$ & $\begin{array}{c}\text { Conversion Cost } \\
\text { [US\$/year] }\end{array}$ & \\
\hline Pretreatment & 711,159 & $1,210,000$ & $1,921,159$ \\
\hline Electrochemical reduction & 856,940 & $1,970,000$ & $2,826,940$ \\
\hline Electrorefining & 322,950 & $1,920,000$ & $2,242,950$ \\
\hline Electrowinning & 485,091 & $1,750,000$ & $2,235,091$ \\
\hline Total & $2,376,140$ & $6,850,000$ & $9,226,140$ \\
\hline
\end{tabular}

Table 11. Raw material cost, conversion cost, and the unit cost of pyroprocess.

\begin{tabular}{|c|c|c|c|c|}
\hline \multirow{2}{*}{$\begin{array}{c}\text { Category } \\
\text { Process Name }\end{array}$} & \multicolumn{2}{|c|}{ Process cost } & \multirow{2}{*}{$\begin{array}{c}\text { Unit Cost } \\
\text { [US\$/kgU-TRU] }\end{array}$} & \multirow{2}{*}{$\begin{array}{c}\text { Cost } \\
\text { Ratio (\%) }\end{array}$} \\
\hline & $\begin{array}{c}\text { Raw Material Cost } \\
\text { [US\$/kgU-TRU] }\end{array}$ & $\begin{array}{l}\text { Conversion Cost } \\
\text { [US\$/kgU-TRU] }\end{array}$ & & \\
\hline Pretreatment & 71 & 124 & 195 & 20.46 \\
\hline Electrochemical reduction & 107 & 203 & 310 & 32.63 \\
\hline Electrorefining & 36 & 179 & 215 & 22.65 \\
\hline Electrowinning & 54 & 177 & 231 & 24.26 \\
\hline Total & 268 & 683 & 951 & 100 \\
\hline
\end{tabular}

Moreover, the conversion cost, which includes the labor cost, takes up $72 \%$ of the pyroprocess cost, and the raw material cost takes up $28 \%$. In the end, the pyroprocess cost that added up the unit cost of each unit process was calculated as $951 \mathrm{US} \$ / \mathrm{kgU}-\mathrm{TRU}$. According to the report of Argonne National Laboratory (ANL), the pyroprocessing cost was estimated to be $1000 \mathrm{US} \$ / \mathrm{kgU}-\mathrm{TRU}$ [27]. Therefore, the cost estimation result of this study seems to be reasonable.

\section{Conclusions}

The purpose of this paper was to identify the cost incurred at each unit process of a pyroprocessing facility. Toward this end, the pyroprocess was classified into four processes, pretreatment, electrochemical reduction, electrorefining and electrowinning, and the cost of each unit process was calculated. This paper adopted a process costing method. The process costing method was subjected to a comparative analysis. Moreover, the First-In, First-Out cost calculation method was used to calculate the unit cost of each process. 
The PRIDE facility was set as the cost object for a cost calculation that can produce $9054 \mathrm{kgHM} /$ year uranium ingot. It was possible to increase cost calculation's accuracy level because the labor cost and expenses that were incurred in this facility could be applicable to the actual process. The following calculations were made: pretreatment at $195 \mathrm{US} \$ \mathrm{kgU}-\mathrm{TRU}$, electrochemical reduction at $310 \mathrm{US} \$ / \mathrm{kgU}-\mathrm{TRU}$, electrorefining at $215 \mathrm{US} \$ \mathrm{kgU}-\mathrm{TRU}$, and electrowinning at $231 \mathrm{US} \$ / \mathrm{kgU}-\mathrm{TRU}$. The cost share of each unit process of the pyroprocess was calculated as a pretreatment of $20.46 \%$, electrochemical reduction of $32.63 \%$, electrorefining of $22.65 \%$, and electrowinning of $24.26 \%$. Accordingly, electrochemical reduction process required the most cost, followed by the cost of the electrowinning process. The difference between the electrorefining and electrowinning is not very significant from the cost share aspect, and the pretreatment unit process consumes the smallest cost.

In particular, the main reason why the cost for the electrochemical reduction process is the highest is because platinum, which is the material of the anode electrode, is very expensive. Moreover, among the raw material costs for the $\mathrm{LiCl}-\mathrm{KCl}$ purification process $\mathrm{Li}_{3} \mathrm{PO}_{4}$ is also an expensive material, and it was identified as the raw material cost's key cost driver. The ratios of material costs of Pt and $\mathrm{Li}_{3} \mathrm{PO}_{4}$ to the unit cost of each process were $20 \%$ and $14 \%$, respectively.

The pyroprocessing cost for the PRIDE facility was calculated as $951 \mathrm{US} / \mathrm{kgU}-\mathrm{TRU}$. Although this value is not that of a commercial facility, it is the process cost for a pyroprocessing facility of engineering scale, which is the stage that lies before the commercial facility. Since the raw material cost and labor cost are actual costs, the cost accuracy level and reliability are very high compared to the pyroprocessing cost, which is estimated based on the existing conceptual design. According to an ANL report, the pyroprocessing cost was estimated to be 1000 US\$/kgU-TRU [27]. Therefore, the cost estimation results of this study seem to be reasonable.

\section{Acknowledgments}

This work was supported by the National Research Foundation of Korea (NRF) grant funded by the Korea government (MSIP: Ministry of Science, ICT and Future Planning), and the authors express their sincere gratitude for supporting this important work.

\section{Author Contributions}

The main theme of this paper was developed by Sungki Kim and was coordinated by Sungsig Bang. Sungki Kim wrote the manuscript and Sungsig Bang prepared most of the equations, tables, figures and submission process of this paper. Wonil Ko commented on the results and conclusions. All the authors reviewed the manuscript.

\section{Conflicts of Interest}

The authors declare no conflict of interest.

\section{Terminology}

Terminologies are as follows [28-30]: 
Allocation cost

Annual availability (availability considering O\&M)

Completeness level

Cost element

Cost flow

Cost object

Direct cost

Ending WIP cost

Equivalent units of product

Expenses

Finished current WIP

Finished product cost

Finished WIP

Indirect cost

Initial stage of the product Initial WIP

Load factor

Overhead cost
Allocation means that an indirect cost is assigned to a cost object by using a reasonable and convenient method

Annual availability means the load factor of PRIDE facility considering the operating $\&$ maintenance periods

It means the degree of completion

Cost element is the components that make up the cost.

Here, it consists of direct material costs and conversion costs (direct labor cost, manufacturing overhead costs)

Cost flow means the method in which costs move from beginning to end in a process. Cost flow does not mean the physical flow but accounting assumptions such as weighted average method and First-In, First-Out method

A cost object is any item such as a product, department, plant, and so on for which costs are measured and assigned

Direct costs are those costs that can be easily and accurately traced to a cost object

Ending WIP cost means costs of the incomplete units on hand at the end of the period

Equivalent units is a derived amount of output units that

(1) takes the quantity of each input in units completed and in incomplete units of WIP and (2) converts the quantity of input into the amount of completed output units that could be produced with that quantity of input. In the end, equivalent units is determined to physical units and completeness level

(Equivalent units $=$ physical units $\times$ completeness level)

Here, expenses mean the indirect costs used in the manufacturing process. Examples of expenses include depreciation cost on buildings and equipment, janitorial and maintenance labor, plant supervision, materials handling, power for plant utilities, and plant property taxes

Finished current WIP means the units which are started and completed during the current period

Finished product cost represents the total product cost of goods completed during the current period and transferred to finished goods inventory

Finished WIP mean the completed units during the period

Indirect costs are costs that cannot be easily and accurately traced to a cost object

It means the beginning of the product (assembly) process

Initial WIP means the incomplete units on hand at the beginning of the period

The ratio of operation (operating hour divided by calendar hour)

Overhead item does not have the direct relationship with units produced that direct materials and direct labor do. The cost of these items means overhead cost 
Overnight cost

Predetermined overhead rate

Processing activity level

Recovery rate

Transferred-in cost

Unit cost

WIP (Work-In Process)
The overnight cost is what a plant would cost to build if it could be completed overnight

The predetermined overhead rate is calculated by dividing the total estimated annual overhead cost by the total estimated level of associated activity level. Activity level may be stated in terms of direct labor costs, direct labor hours, machine hours, or any other measure that will provide an equitable basis for applying overhead costs to jobs

It means completeness level

The recovery rate is the amount of recovered material divided by the total amount of input materials

Transferred-in cost is costs transferred from a prior process to a subsequent process

The unit cost is the total cost divided by the number of units WIP is the cost of the partially completed goods that are still on the factory floor at the end of a time period

\section{References}

1. Tasić, M.B.; Stamenković, O.S.; Veljković, V.B. Cost analysis of simulated base-catalyzed biodiesel production processes. Energy Convers. Manag. 2014, 84, 405-413.

2. Alalm, M.G.; Tawfik, A.; Ookawara, S. Degradation of four pharmaceuticals by solar photo-Fenton process: Kinetics and costs estimation. J. Environ. Chem. Eng. 2015, 3, 46-51.

3. Nakaten, N.; Schlüter, R.; Azzam, R.; Kempka, T. Development of a techno-economic model for dynamic calculation of cost of electricity, energy demand and $\mathrm{CO}_{2}$ emissions of an integrated UCG-CCS process. Energy 2014, 66, 779-790.

4. Sovacool, B.K. Cornucopia or curse? Reviewing the costs and benefits of shale gas hydraulic fracturing (fracking). Renew. Sustain. Energy Rev. 2014, 37, 249-264.

5. Middleton, R.; Viswanathan, H.; Currier, R.; Gupta, R. $\mathrm{CO}_{2}$ as a fracturing fluid: Potential for commercial-scale shale gas production and $\mathrm{CO}_{2}$ sequestration. Energy Procedia 2014, 63, 7780-7784.

6. Xia, L.; Luo, D.; Yuan, J. Exploring the future of shale gas in China from an economic perspective based on pilot areas in the Sichuan basin-A scenario analysis. J. Nat. Gas. Sci. Eng. 2015, 22, 670-678.

7. Kim, S.K.; Ko, W.I.; Lee, Y.H. Economic viability of metallic sodium-cooled fast reactor fuel in Korea. Sci. Tech. Nucl. Install. 2013, 2013, doi:10.1155/2013/412349.

8. Hyundai Engineering Co, Ltd. The Development of Cost Estimation System for Nuclear Liability; Hyundai Engineering Co, Ltd: Seoul, Korea, 2009.

9. Korea Atomic Energy Research Institute (KAERI). Preliminary Conceptual Design and Cost Estimation for Korea Advanced Pyroprocess Facility Plus (KAPF+); KAERI: Daejeon, Korea, 2011.

10. Lee, H.S.; Park, G.I.; Lee, J.W.; Kang, K.H.; Hur, J.M.; Kim, J.G.; Paek, S.W.; Kim, I.T.; Cho, I.J. Current status of pyroprocessing development at KAERI. Sci. Tech. Nucl. Install. 2013, 2013, 1-11. 
11. Kim, S.K.; Ko, W.I.; Lee, Y.H. Development and validation of a nuclear fuel cycle analysis tool: a future code. Nucl. Eng. Tech. 2013, 45, 665-674.

12. Organization for Economic Cooperation and Development/Nuclear Energy Agency (OECD/NEA). The Economics of the Back-End of the Nuclear Fuel Cycle; OECD/NEA: Paris, France, 2013.

13. Shropshire, D.E.; Williams, K.A.; Boore, W.B.; Smith, J.D.; Dixon, B.W.; Dunzik-Gougar, M.; Adams, R.D.; Gombert, D. Advanced Fuel Cycle Cost Basis; Idaho National Laboratory (INL): Idaho Falls, ID, USA, 2007.

14. American Association of Clinical Endocrinologists (AACE). Skills \& Knowledge of Cost Engineering-Appendix E3; AACE International Press: Morgantown, WV, USA, 2004.

15. Chwastyk, P.; Kołosowski, M. Estimating the cost of the new product in development process. Procedia Eng. 2014, 69, 351-360.

16. Agyapong-Kodua, K.; Asare, K.B.; Ceglarek, D.J. Digital modelling methodology for effective cost assessment. Procedia CIRP 2014, 17, 744-749.

17. Martinho, R.; Domingos, D. Quality of information and access cost of IoT resources in BPMN processes. Procedia Tech. 2014, 16, 737-744.

18. Weschenfelder, S.E.; Mello, A.C.C.; Borges, C.P.; Campos, J.C. Oilfield produced water treatment by ceramic membranes: Preliminary process cost estimation. Desalination 2015, 360, 81-86.

19. Park, J.D. Fundamental Cost Management Accounting; Hyungseul Press: Daegu, Korea, 2005.

20. Kang, S.J. The Theory of Cost Estimation; Dunam Press: Seoul, Korea, 2010.

21. Mowen, M.M.; Hansen, D.R.; Heitger, D.L. Managerial Accounting: The Cornerstone of Business Decisions; South-Western Press: Nashville, TN, USA, 2012.

22. Humphreys, K.K. The cost engineering profession. J. Cost Anal. 1984, 1, 143-147.

23. Shin, H.G. Intermediate Accounting; Tamjin Press: Seoul, Korea, 2005.

24. Massachusetts Institute of Technology (MIT). The Future of the Nuclear Fuel Cycle; MIT: Cambridge, MA, USA, 2011.

25. Park, Y.T. Engineering Economics; Cheongmoongak Press: Paju, Korea, 2008.

26. Challal, A.; Tkiouat, M. The design of cost estimating model of construction project: Application and simulation. Open J. Account. 2012, 1, 15-26.

27. Yoon, C. Economic/Business Case for the Pyroprocessing of Spent Nuclear Fuel (SNF); Argonne National Laboratory: Argonne, WI, USA, 2010.

28. Horngren, C.T.; Datar, S.M.; Foster, G.; Rajan, M.V.; Ittner, C. Cost Accounting: A Managerial Emphasis; Pearson Education: Upper Saddle River, NJ, USA, 2009.

29. Mowen, M.M.; Hansen, D.R.; Heitger, D.L. Cornerstones of Managerial Accounting; Cengage Learning: Boston, MA, USA, 2014.

30. Weygandt, J.J.; Kieso, D.E.; Kimmel, P.D. Accounting Principles; Wiley: Danvers, MA, USA, 2008.

(C) 2015 by the authors; licensee MDPI, Basel, Switzerland. This article is an open access article distributed under the terms and conditions of the Creative Commons Attribution license (http://creativecommons.org/licenses/by/4.0/). 